УДК 630.282 .1

\title{
ИЗУЧЕНИЕ ХИМИКО-ТЕХНОЛОГИЧЕСКИХ СВОЙСТВ ЭТАНОЛЬНОГО ЭКСТРАКТА СОСНЫ, ПОЛУЧЕННОГО ИЗ ОКОРКИ ДРЕВЕСИНЫ, И ЕГО ВОЗМОЖНОГО ПРИМЕНЕНИЯ В КОЖЕВЕННО-МЕХОВОЙ ПРОМЫШЛЕННОСТИ
}

\author{
(C) Н.В. Гончарова“", Н.В. Сячинова, Е.А. Думнова
}

\author{
Восточно-Сибирский государственный университет технологий \\ и управления, ул. Ключевская, 40в, Улан-Удэ, 670013 (Россия), \\ e-mail: natvic@list.ru,tkm_tnt@mail.ru
}

В работе изучалось влияние этилового спирта на качественный состав экстракта сосны, полученного из низкосортного сырья и его технологические свойства. Изучалось наличие взаимосвязи между видом экстрагента и степенью модификации коллагена - основного белка шкур при помощи моделирования процесса дубления. В качестве модели использовали продукты растворенного коллагена (ПРК) обработанные этиловым экстрактом сосны. Степень модификации определяли методом дифференциально-сканирующей калориметрии (ДСК). В результате проведенных исследований выявлено, что спиртовой экстракт сосны отличается большим содержанием смолистых веществ, а также характеризуется высокой степенью доброкачественности $(\sim 92,6 \%)$. Взаимодействие экстрактивных веществ с коллагеном идет преимущественно по амидному азоту и боковым карбоксильным группам, при этом высвобождаются $\varepsilon-$ аминогруппы и фенольные гидроксильные группы, которые ранее вероятно были заблокированные водородными связями. Термостойкость пленок, полученных на основе дубленых ПРК достаточно высока, что позволяет сделать вывод о возможном применении спиртовых экстрактов сосны в кожевенно-меховой промышленности в качестве дубящего агента.

Ключевые слова: продукт растворенного коллагена (ПРК), дифференциально-сканирующая калориметрия, экстракт сосны

\section{Введение}

Территория Восточной Сибири богата лесами, что способствует развитию лесозаготовительной и деревоперерабатывающей отрасли. Основной упор деревоперерабатывающая промышленность Сибирского региона в целом делает на заготовку хвойных пород деревьев, в частности на сосну. Заготовка деловой древесины сопровождается образованием большого количества отходов в виде окорки, которые из-за низких качественных характеристик не перерабатываются экстрактовыми заводами. Водная экстракция, применяемая большинством предприятий, задействованных в переработке окорки древесины, не позволяет в полной мере извлекать весь комплекс содержащихся в сосновой коре химических веществ, что делает нецелесообразной ее промышленную переработку. В лучшем случае такие отходы сжигаются, в худшем - скапливаются на территории предприятия, создавая угрозу экологической и пожарной безопас-

Гончарова Наталья Викторовна - доцент кафедры «Технология кожи, меха. Водные ресурсы и товароведение», кандидат технических наук, тел.: (3012)41-72-22, e-mail: natvic@list.ru, tkm_tnt@mail.ru

Сячинова Наталья Владимировна - старший преподаватель кафедры неорганической и аналитической химии, кандидат химических наук, e-mail: c-h-v@mail.ru

Думнова Екатерина Александровна - студентка ности. Замена растворителя в процессе экстракции может привести к значительному увеличению степени извлечения веществ из окорки древесины, а это, в свою очередь, приведет к расширению сырьевой базы экстрактовых предприятий за счет низкосортного сырья.

Растительные экстракты, используемые в кожевенно-меховой промышленности, характеризуют-

\footnotetext{
* Автор, с которым следует вести переписку.
} 
ся сложным химическим составом. Экстрактивные вещества отличаются друг от друга не только своим строением, но и химической активностью, благодаря которой они в большей или меньшей степени способны модифицировать коллаген в процессе таннидного дубления. Дубящими свойствами обладают вещества полифенольной природы, альдегиды, непредельные жиры, производные целлюлозы (в частности ацетатцеллюлоза), однако механизм их взаимодействия с дермой в значительной мере отличается друг от друга [1]. Согласно литературным источникам [2, 3] в коре сосны содержится большое количество фенольных соединений, а также непредельных веществ, обладающих определенной химической активностью. Кроме того, отличительной особенностью сосновой коры является высокое содержание в ней смолистых веществ [3], которые, по мнению авторов, также могут проявлять дубящие свойства.

Цель исследования - изучение химико-технологических свойств этанольных экстрактов сосны, полученных из низкосортного сырья, и возможности их применения в кожевенно-меховой промышленности в качестве дубителя.

Задачи исследования:

- изучение влияния этанола на качественные характеристики получаемых экстрактов сосны;

- исследование характера взаимодействия полученных экстрактов с коллагеном;

- оценка степени модификации структуры дермы в процессе дубления этанольными экстрактами сосны.

\section{Экспериментальная часть}

Объектом исследования являлся этанольный экстракт сосны, полученный по следующей схеме: кору, измельченную до размера 2,5-4 мм³, заливали 96\%-ным этиловым спиртом. Температура экстракции составляла $70{ }^{\circ} \mathrm{C}$ при жидкостном модуле, равном 8. Экстракт получали методом настаивания в течение 1 ч. По истечении указанного времени полученный раствор отделяли от отдубины путем фильтрования и определяли его качественные характеристики, используя типовые методики [4]. Результаты анализа представлены в таблице 1 .

\section{Обсуждение результатов}

Исследования показали, что выход экстрактивных веществ из коры сосны при использовании этанола составляет $7 \%$ (в пересчете на абсолютно сухое вещество), что значительно превышает данный показатель, наблюдаемый при водной экстракции ( 3-4\%) [5]. Проведенный анализ полученного экстракта выявил наличие большого содержания таннидов - соединений, обладающих дубящей способностью ( 92,1\%), которые по классификации Г.Г. Поварнина можно отнести к пирокатехиновому ряду [3, 6]. Высокий показатель доброкачественности полученного экстракта ( 92,6\%) делает его привлекательным для использования в качестве дубителя в кожевенно-меховом производстве.

Свойства готового кожевенно-мехового полуфабриката во многом зависят от характера взаимодействия дубящих веществ с функциональными группами коллагена - основного белка кожного покрова шкур. Дубление является сложным не только химическим, но и физическим процессом, при котором коллаген претерпевает существенные структурные изменения. Качественный состав растительных экстрактов влияет на механизм связывания таннидов с дермой. Для определения вида взаимодействия, которое будет происходить между таннидами, содержащимися в спиртовом экстракте сосны, и кожевой тканью в процессе дубления был использован метод потенциометрического титрования, основанный на определении изменения количества свободных функциональных групп, содержащихся в нативном и дубленом коллагене [7].

Таблица 1. Влияние природы растворителя на качественные характеристики сосновых экстрактов

\begin{tabular}{l|c}
\hline \multicolumn{1}{c|}{ Показатель качества } & Этанольный экстракт сосны \\
\hline Степень извлечения экстрактивных веществ из коры, считая на а.с.в., \% & 7,0 \\
Значение водородного показателя полученного экстракта, рН & 4,2 \\
Экстрактивные вещества, \%: & 100,0 \\
- растворимые вещества (ВР), \% & 100,0 \\
- танниды (Т), \% & 92,1 \\
- нетанниды (НТ), \% & 7,9 \\
Нерастворимые вещества (НР), \% & - \\
Доброкачественность (Д), \% & 92,6 \\
\hline
\end{tabular}


Данные исследования проводились на модельном растворе, содержащем продукты растворенного коллагена (ПРК), который по своим химическим характеристикам является аналогом нативного коллагена. Результаты проведенных исследований представлены в таблице 2.

Из данных таблицы 2 видно, что дубящие вещества, содержащиеся в сосновом экстракте, преимущественно взаимодействуют с боковыми карбоксильными группами, присутствующими в белке в свободном состоянии, а также по амидному азоту. В процессе дубления также блокируются концевые $\alpha$-аминогруппы, содержащиеся в продуктах растворения коллагена в незначительном количестве. Одновременно с этим в процессе дубления происходит высвобождение $\varepsilon$-аминогупп и фенольных гидроксильных групп, активность которых, возможно, ранее блокировалась водородными связями, в большом количестве содержащимися в изучаемой системе. Прочность химических связей, образующихся между функциональными группами дубителя и коллагена, влияет на сроки эксплуатации кожевенно-мехового полуфабриката. Сложно-компонентный состав спиртового экстракта способствует образованию разнообразных связей (ковалентных, электровалентных, водородных), в различной степени способных модифицировать нативный коллаген. Водородные связи обладают слабой энергией активации и во многих случаях не способны прочно фиксировать образовавшуюся в результате химической реакции систему. Поэтому часть дубящих веществ может быть удалена из дермы при следующих после дубления жидкостных обработках или в процессе эксплуатации изделий. Следствием этого может стать преждевременное старение и разрушение кожевенно-мехового полуфабриката.

Качественный состав экстракта влияет не только на степень продубленности полученного полуфабриката, но и на поведение экстракта в процессе хранения на складских помещениях. В некоторых случаях повышение температур может приводить к значительным изменениям химической активности веществ, входящих в состав растительных экстрактов в связи с их деструкцией, вызванной суммарным действием высоких температур и окислением кислородом воздуха. Поэтому необходимо провести исследование влияния качественного состава этанольного экстракта сосны на технологические характеристики, связанные с возможностью хранения дубителя и степенью модификации коллагена, обусловленной прочностью образующихся связей таннидов с дермой. Наибольшую информацию в этой области могут дать исследования, предусматривающие использование метода дифференциально-сканирующей калориметрии (ДСК). Метод ДСК позволяет оценить термостойкость веществ, а также выявить кинетические параметры процесса деструкции вещества: энергию активации $E_{a}$ и порядок реакции $n[8,9]$.

Анализ ДСК спиртового экстракта сосны и пленок, полученных на основе ПРК, выдубленных с применением данного экстракта, проводили на дериватографе NETZSCH STA 449 C. Полученные в результате исследования кривые представлены на рисунке.

Термостабильность, или термостойкость, оценивается температурой начала разложения вещества. Процесс деструкции сопровождается потерей массы (кривая ТГ). Кривая ДТГ характеризует термические эффекты, происходящие в системе при ее термическом разрушении. На полученных при помощи анализа ДСК кривых, описывающих термостойкость спиртового экстракта сосны и пленок ПРК, дубленных с его применением, наблюдается несколько ступеней, соответствующих различным этапам разложения вещества и характеризующихся своими тепловыми эффектами. Количество ступеней для каждой системы свое, что обусловлено не только химическим составом, но и степенью их кристалличности. Первая ступень разложения для наших систем на кривых ТГ (см. рис.) наблюдается в области температур $\sim 50{ }^{\circ} \mathrm{C}$, что соответствует реакции дегидратации и испарению растворителя, адсорбированного за счет физической природы взаимодействия. Данный процесс, судя по направлению пиков полученных кривых ДТГ (см. рис.), является эндотермическим. Последующие ступени разложения (ТГ) соответствуют экзотермическим эффектам (ДТГ), обусловлены окислением и структурным превращением в системе.

Таблица 2. Взаимодействие соснового экстракта с функциональными группами белка

\begin{tabular}{l|c|c|c}
\hline \multicolumn{1}{c|}{ Функциональные группы } & \multirow{2}{*}{\begin{tabular}{c} 
Содержание функциональных групп белка, ммоль/100 г белка \\
\cline { 3 - 4 }
\end{tabular}} & раствор ПРК & $\begin{array}{c}\text { раствор ПРК, обработанный } \\
\text { спиртовым сосновым экстрактом }\end{array}$ \\
\hline $\begin{array}{l}\text { Боковые карбоксильные группы, при- } \\
\text { сутствующие в свободном состоянии }\end{array}$ & $1,5-6,0$ & 62,69 & 36,49 \\
$\begin{array}{l}\text { Взаимодействие протонов с концевы- } \\
\text { ми } \alpha \text {-аминогруппами }\end{array}$ & $6,0-8,5$ & 0,98 & 0,00 \\
$\begin{array}{l}\varepsilon \text {-аминогуппы, фенольные гидро- } \\
\text { ксильные группы }\end{array}$ & $8,5-12,0$ & 58,45 & 60,74 \\
Содержание амидного азота & - & 61,71 & 36,49 \\
\hline
\end{tabular}




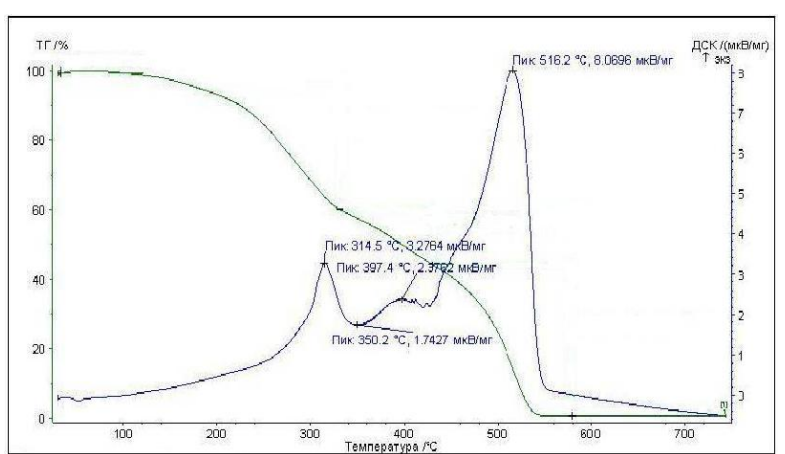

a)

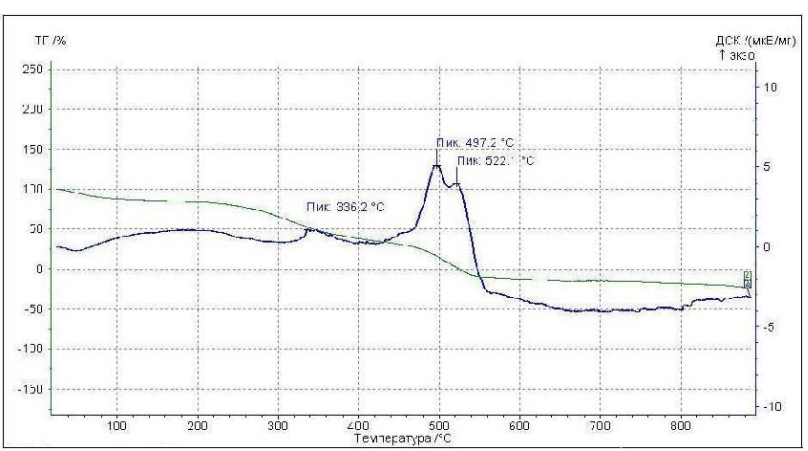

б)

Кривые, полученные с помощью ДСК. Термограммы: а - спиртового экстракта сосны; б - пленок ПРК, дубленных спиртовым экстрактом сосны

Из рисунка видно, что термодеструкция как самого спиртового экстракта, так ПРК, дубленных с его применением, происходит в три этапа. На первом этапе происходит удаление летучих веществ, на втором терморазложение образцов, на третьем - удаление продуктов термодеструкции.

По данным анализа ДСК методом двойного логарифмирования [8] рассчитаны энергии активации химических реакций, сопровождающих процесс деструкции дубленных ПРК, которые приведены в таблице 3.

Для пленки ПРК, обработанной спиртовым экстрактом сосны, максимальная температура разложения наблюдается при $550{ }^{\circ} \mathrm{C}$. Процесс разложения сопровождается тремя экзотермическими эффектами (кривая ДТГ), что соответствует двум ступеням уменьшения пробы (ТГ). Последняя ступень термодеструкции (ТГ) характеризуется двумя экзотермическими эффектами (ДТГ), связанными с неоднородностью макромолекул, образовавшихся в результате взаимодействия экстрактов с ПРК. Сложный состав экстракта сосны, а также большое содержание в его составе смолянистых веществ приводят к образованию с ПРК кристаллитов различной модификации. Увеличение степени кристалличности биополимера ведет к повышению его сопротивления к негативному воздействию окружающей среды и увеличивает срок его эксплуатации.

Таблица 3. Рассчитанные энергии активации спиртового экстракта сосны и ПРК дубленных спиртовым экстрактом сосны

\begin{tabular}{c|c|c|c}
\hline $\begin{array}{c}\text { Ступени } \\
\text { термодеструкции }\end{array}$ & $\begin{array}{c}\text { Температурный } \\
\text { интервал }\end{array}$ & $\begin{array}{c}\text { Уменьшение массы исследуемого } \\
\text { образца дубленных ПРК }\end{array}$ & $\begin{array}{c}\text { Энергия активации } E_{a}, \\
\text { кДж/моль }\end{array}$ \\
\hline \multicolumn{4}{|c}{ Спиртовой экстракт сосны } \\
\hline II ступень & $208-358$ & 35,71374 & 32,761 \\
III ступень & $368-428$ & 10,53021 & 90,857 \\
IV ступень & $438-558$ & 42,38580 & 128,879 \\
\hline \multicolumn{5}{c}{ Пленка ПРК, обработанная спиртовым экстрактом сосны } \\
\hline II ступень & $181-421$ & 49,11623 & 29,283 \\
III ступень & $431-551$ & 43,83510 & 119,395 \\
\hline
\end{tabular}

\section{Заключение}

Таким образом, проведенные исследования показали, что спиртовой экстракцией можно значительно увеличить степень извлечения веществ, содержащихся в коре сосны, что позволить повысить рентабельность промышленной переработки низкосортных отходов окорки древесины сосны экстрактовыми заводами. Кроме этого, спиртовая экстракция позволяет получать из коры сосны дубитель, пригодный для обработки шкур.

\section{Список литературь}

1. Страхов И.П., Шестакова И.С., Куциди Д.А. и др. Химия и технология кожи и меха / под ред. проф. И.П. Страхова. 3-е изд. перераб. и доп. М., 1979. 504 с.

2. Дейнеко И.П., Дейнеко Л.П., Белов Л.П. Исследование химического состава коры сосны // Химия растительного сырья. 2007. №1. С. 19-24. 
3. Рязанова Т.В., Репях С.М. Химия и технология коры хвойных : монография: в 2 ч. Ч. 1: Химия и использование коры. Красноярск, 2010. 160 с.

4. ГОСТ 28508-90. Экстракты дубильные растительные. Методы определения. М., 1990.

5. Гончарова Н.В., Сячинова Н.В., Думнова Е.А. Изучение влияния природы экстрагента на качественные характеристики сосновых экстрактов // Кожа и мех в XXI веке: технология, качество, экология образование : материалы V Междун. научно-практической конференции. Улан-Удэ, 2009. С. 68-73.

6. Гончарова Н.В. Растительные экстракты: комплексный анализ : методические указания по курсу «Химия и технология кожи и меха» для студентов специальности 260904 «Технология кожи и меха». Улан-Удэ, 2011. 83 с.

7. Аналитические методы белковой химии. М., 1963. 309 с.

8. Уэндландт У. Термические методы анализа. М., 1978, 526 с.

9. Пилоян Г.О., Новикова О.С. Вычисление кинетических параметров по данным дериватографических измерений // Журнал неорганической химии. 1967. Вып. 12. С. 602-605.

Поступило в редакцию 12 марта 2013 г.

Goncharova N.V., Siachinova N.V., Dumnova E.A. THE STUDY OF CHEMICAL AND TECHNOLOGICAL PROPERTIES OF THE ETHANOL EXTRACT OF PINE OBTAINED FROM DEBARKING AND ITS POSSIBLE APPLICATION IN THE LEATHER AND FUR INDUSTRY

East-Siberian State University of Technology and Management, yл. Kliuchevskaia st., 40v, Ulan-Ude, 670013 (Russia), e-mail:natvic@list.ru,tkm_tnt@mail.ru

This paper investigated the effect of ethanol on the quality of the extract of pine produced from low-grade raw materials and their processing properties. We studied the relationship between views of the extractant and the degree of modification of collagen - the main skins' protein by simulating the process of tanning. The products of dissolution of collagen (PDC) treated with ethyl extract of pine were used as the model. The degree of modification was determined by differential scanning calorimetry. The investigations revealed that the alcohol extract of pine features a large tar content and a high degree of purity $(\sim 92,6 \%)$. Interaction between extractives and collagen goes mainly on amide nitrogen and the side carboxyl groups, with $\varepsilon-$ amino groups and phenolic hydroxyl groups - that have probably been blocked by hydrogen bondsare - are being released. Heat resistance of coats derived from the tanned PDC is high enough, it can be concluded that there may be the possible use of alcohol extracts of pine in the leather and fur industry as a tanning agent.

Keywords: The products of dissolution of collagen (PDC), differential scanning calorimetry, extract of pine.

\section{References}

1. Strakhov I.P., Shestakova I.S., Kutsidi D.A. Khimiia i tekhnologiia kozhi i mekha. [Chemistry and technology of leather and fur.]. Ed. I.P. Strakhov. Moscow, 1979. 504 p. (in Russ.).

2. Deineko I.P., Deineko L.P., Belov L.P. Khimiia rastitel'nogo syr'ia, 2007, no. 1, pp. 19-24. (in Russ.).

3. Riazanova T.V., Repiakh S.M. Khimiia i tekhnologiia kory khvoinykh: monografiia v 2-kh chastiakh. Ch. 1. Khimiia i ispol'zovanie kory. [Chemistry and Technology of the bark of conifers: monograph in 2 parts. Part 1 Chemistry and use of bark]. Krasnoyarsk, 2010. 160 p. (in Russ.).

4. GOST 28508-90. Ekstrakty dubil'nye rastitel'nye. Metody opredeleniia. [State standartT 28508-90. Tanning extracts of vegetable. Methods for determination]. Moscow, 1990. (in Russ.).

5. Goncharova N.V., Siachinova N.V., Dumnova E.A. Kozha i mekh v XXI veke: tekhnologiia, kachestvo, ekologiia obrazovanie : materialy V Mezhdunarodnoi nauchno-prakticheskoi konferentsii. [Leather and fur in the XXI century: technology, quality, environmental education: the V International scientific-practical conference]. Ulan-Ude, 2009, pp. 68-73. (in Russ.).

6. Goncharova N.V. Rastitel'nye ekstrakty: kompleksnyi analiz. [Plant extracts: a comprehensive analysis]. Ulan-Ude, 2011, 83 p. (in Russ.).

7. Analiticheskie metody belkovoi khimii. [Analytical methods of protein chemistry]. Moscow, 1963, 309 p. (in Russ.).

8. Uendlandt U. Termicheskie metody analiza. [Thermal methods of analysis]. Moscow, 1978, 526 p. (in Russ.).

9. Piloian G.O., Novikova O.S. Zhurnal neorganicheskoi khimii, 1967, no. 12, pp. 602-605. (in Russ.).

\footnotetext{
${ }^{*}$ Corresponding author.
} 
